\title{
A Proteomics Approach to the Protein Normalization Problem: Selection of Unvarying Proteins for MS-Based Proteomics and Western Blotting
}

\author{
Jacek R. Wiśniewski* ${ }^{*}, \neq \neq$ and Matthias Mann \\ ${ }^{\dagger}$ Biochemical Proteomics Group, ${ }^{\ddagger}$ Department of Proteomics and Signal Transduction, Max Planck Institute of Biochemistry, 82152 \\ Martinsried, Germany
}

\section{Supporting Information}

\begin{abstract}
Proteomics and other protein-based analysis methods such as Western blotting all face the challenge of discriminating changes in the levels of proteins of interest from inadvertent changes in the amount loaded for analysis. Massspectrometry-based proteomics can now estimate the relative and absolute amounts of thousands of proteins across diverse biological systems. We reasoned that this new technology could prove useful for selection of very stably expressed proteins that could serve as better loading controls than those traditionally employed. Large-scale proteomic analyses of SDS
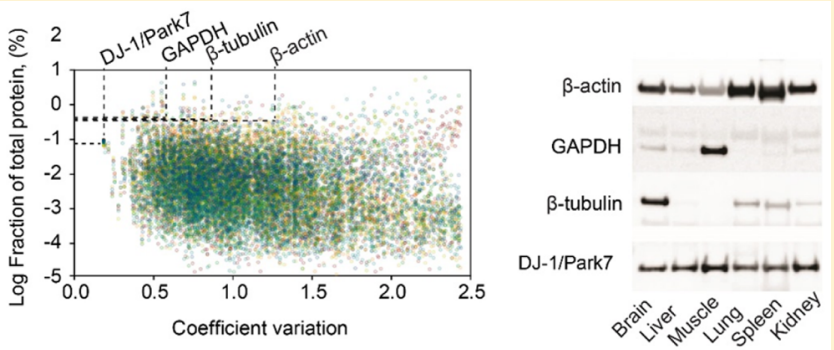
lysates of cultured cells and tissues revealed deglycase DJ-1 as the protein with the lowest variability in abundance among different cell types in human, mouse, and amphibian cells. The protein constitutes $0.069 \pm 0.017 \%$ of total cellular protein and occurs at a specific concentration of $34.6 \pm 8.7 \mathrm{pmol} / \mathrm{mg}$ of total protein. Since DJ-1 is ubiquitous and therefore easily detectable with several peptides, it can be helpful in normalization of proteomic data sets. In addition, DJ-1 appears to be an advantageous loading control for Western blot that is superior to those used commonly used, allowing comparisons between tissues and cells originating from evolutionarily distant vertebrate species. Notably, this is not possible by the detection and quantitation of housekeeping proteins, which are often used in the Western blot technique. The approach introduced here can be applied to select the most appropriate loading controls for MS-based proteomics or Western blotting in any biological system.
\end{abstract}

KEYWORDS: DJ-1, PARK7, "Total Protein Approach", quantitative proteomics, proteomic data normalization, Xenopus, Western blot, loading control

\section{INTRODUCTION}

Western blotting (WB) is one of the most widely used techniques in the life sciences. Employing specific antibodies, the method allows the identification and relative quantification of proteins separated by polyacrylamide gel electrophoresis proteins. ${ }^{1}$ Ubiquitously expressed proteins, such as $\beta$-actin, $\beta$ tubulin, and glyceraldehyde phosphate dehydrogenase (GAPDH), whose levels are thought to remain unchanged, serve as loading controls in WB. However, there are many pitfalls to the technique, which make it semiquantitative at best. ${ }^{2}$ Several studies have found that normalization approaches using integration of total protein blotted appear to be more accurate. $^{3-5}$ In particular, the use of sensitive fluorescent labels allows precise normalization and protein quantitation at a higher dynamic range compared with standard "enhanced chemiluminiscence"-based detection. ${ }^{5}$ Nevertheless, these methods are not commonly employed because of the requirement of specific scanning equipment. In any case, the WB technique remains challenging because of the variability of antibodies, ${ }^{6}$ which mainly reflects their specificity and affinity to antigens. In addition, quantitation with antibodies is usually limited to 1 order of magnitude of antigen concentration.

Mass spectrometry (MS)-based proteomics has become increasingly powerful and now allows the identification and quantification of thousands of proteins in a streamlined and robust manner. In particular, we have recently demonstrated that label-free proteomics using the "total protein approach" allows the determination of concentrations of thousands of proteins. $^{7,8}$ We hypothesized that comparing quantitative proteomic data across diverse cell types and tissues could pinpoint ubiquitously expressed proteins, which could serve as more accurate normalization controls. We report the identification of deglycase DJ-1, a protein that is ubiquitously expressed and occurs with the lowest titer variability in proteomes across tissues and cells of vertebrate organisms.

Received: May 4, 2016

Published: June 13, 2016 

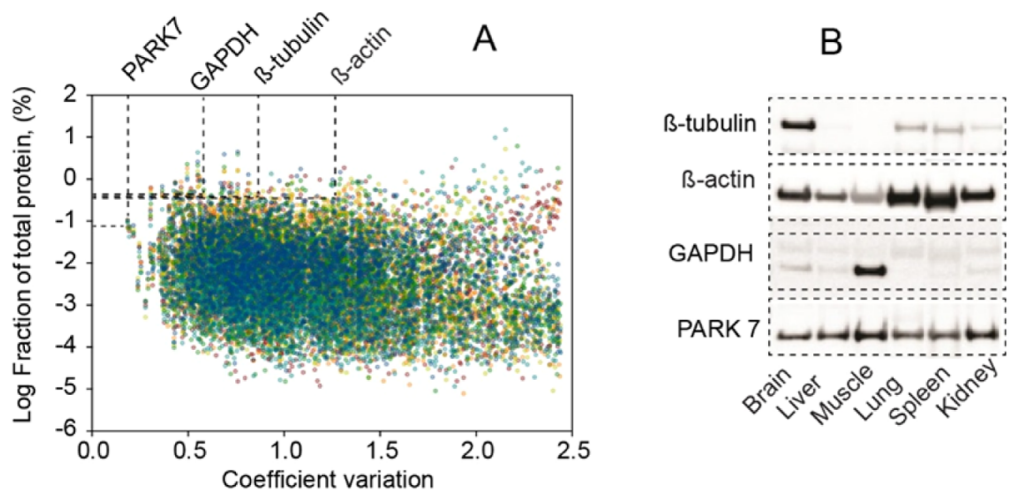

C

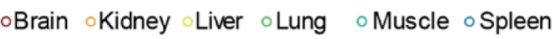

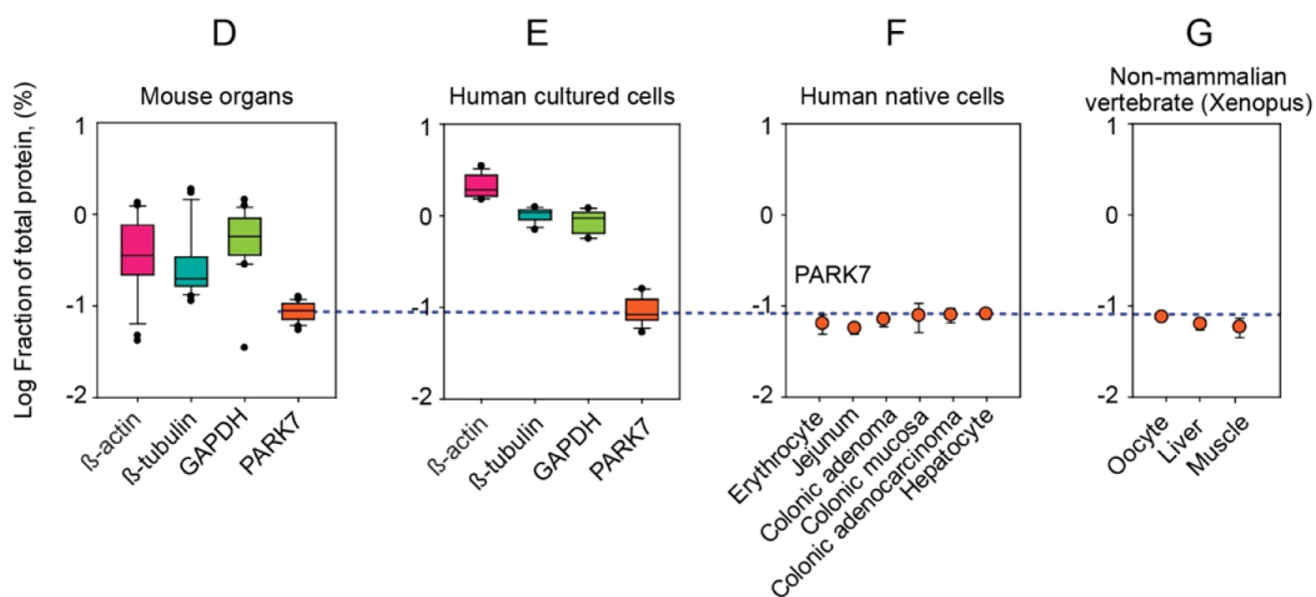

Figure 1. DJ-1 protein is a ubiquitous protein with constant expression in vertebrate cells. (A) Protein abundance vs variation of protein concentration across mouse tissues. For this graph, 2866 proteins identified by LC-MS/MS on an Orbitrap instrument in all of the analyzed tissues were considered. (B, C) Western blot analysis of whole-cell lysates of selected mouse organs cultured using antibodies against $\beta$-actin, $\beta$-tubulin, GADPH, and DJ-1 (PARK7) protein. (D, E) Abundances of $\beta$-actin, $\beta$-tubulin, GADPH, and DJ-1 (PARK7) protein in mouse organs and human cell lines (current study). (F) Abundance of DJ-1 protein in native human cells (meta-analysis; for references, see Table S1). (G). Abundance of DJ1 (PARK7) protein in the nonmammalian vertebrate Xenopus laevis (current study).

\section{EXPERIMENTAL PROCEDURES}

\section{Tissue Isolation and Lysis}

Mouse (10-week-old female C57BL/6 mice were bred on a 12 $\mathrm{h} / 12 \mathrm{~h}$ light/dark cycle and had free access to standard chow diet) and Xenopus laevis organs and cultured human cells were lysed in a buffer containing $0.1 \mathrm{M}$ Tris $-\mathrm{HCl}(\mathrm{pH} 7.4), 2 \%$ SDS, and $0.05 \mathrm{M}$ DTT as described previously. ${ }^{9}$ The animals were bred at the Institute's Animal Facility. Whole organs were homogenized with Ultra Turrax T8 homogenizer (IKA Labotechnik). For muscle lysate, the entire gastrocnemius was used. The cells were directly lysed in the buffer. Total protein content in the lysates was determined by means of a tryptophan fluorescence (WF) assay. ${ }^{10}$

\section{Protein Digestion}

Protein lysates were processed using the MED-FASP protocol $^{11}$ with modifications described recently. ${ }^{12}$ Briefly, aliquots containing $50 \mu \mathrm{g}$ of total protein were mixed with 200 $\mu \mathrm{L}$ of $8 \mathrm{M}$ urea in $0.1 \mathrm{M}$ Tris/ $\mathrm{HCl}(\mathrm{pH} 8.5)$ (UA) in the Microcon $30 \mathrm{~K}$ ultrafiltration unit and then centrifuged at $10000 \mathrm{~g}$ at $18{ }^{\circ} \mathrm{C}$ for $15 \mathrm{~min}$. The eluates were discarded, 100 $\mu \mathrm{L}$ of $\mathrm{UA}$ was pipetted into the filtration unit, and the units were centrifuged again. Then $50 \mu \mathrm{L}$ of $0.05 \mathrm{M}$ iodoacetamide in UA was added to the filters, and the samples were incubated in darkness for $20 \mathrm{~min}$. The filters were washed twice with $100 \mu \mathrm{L}$ of UA followed by two washes with $100 \mu \mathrm{L}$ of $0.05 \mathrm{M}$ Tris/HCl ( $\mathrm{pH} 8.5$ ) (digestion buffer, DB) and were digested in $40 \mu \mathrm{L}$ of the buffer used for washing at $37{ }^{\circ} \mathrm{C}$ for $18 \mathrm{~h}$ using endoproteinase LysC (MED FASP) at an enzyme to protein ratio of 1:50. The released peptides were collected by centrifugation at $10000 \mathrm{~g}$ for $10 \mathrm{~min}$ followed by two washes with $100 \mu \mathrm{L}$ of $\mathrm{DB}$. The material remaining on the filter was digested with trypsin using the above conditions, except that the cleavage reaction was performed for only $2 \mathrm{~h}$. The peptide eluates containing $10 \mu \mathrm{g}$ of total peptide were concentrated to a volume of $4-5 \mu \mathrm{L}$ and were stored frozen at $-20 \mathrm{C}$ until mass spectrometric analysis. Peptides were quantified by the WF assay. $^{10}$

\section{LC-MS/MS Analysis}

Analysis of the peptide mixtures was performed in an LTQ Orbitrap instrument (Thermo Fisher Scientific) as described previously. ${ }^{9,13}$ Briefly, aliquots containing $6-8 \mu \mathrm{g}$ of peptides were injected and separated on a reversed-phase column (20 $\mathrm{cm} \times 75 \mu \mathrm{m}$ inner diameter) packed with $1.8 \mu \mathrm{m}$ C18 particles (Dr. Maisch GmbH, Ammerbuch-Entringen, Germany) using a $4 \mathrm{~h}$ acetonitrile gradient in $0.1 \%$ formic acid at a flow rate of $250 \mathrm{~nL} / \mathrm{min}$. The LC was coupled to the mass spectrometer via a nanoelectrospray source (Thermo Fisher Scientific). The 
LTQ Orbitrap instrument was operated in data-dependent mode with survey scans acquired at a resolution of 60000 at $\mathrm{m} /$ $z$ 400. For collision-induced dissociation (CID) fragmentation, up to the 10 most abundant precursor ions from the survey scan with charge $\geq+2$ within the $m / z 300-1700$ range were selected. The normalized collision energy was 35 . The dynamic exclusion parameters were $90 \mathrm{~s}$ and $5 \mathrm{ppm}$. The MS/MS spectra were acquired in the linear ion trap.

\section{Data Analysis}

The MS data from mouse and human material were analyzed using the MaxQuant software ${ }^{14}$ (version 1.5.3.14). Proteins were identified by searching MS and MS/MS data for peptides (54 658 peptides in mouse tissues, 49726 in human cell lines, and 25502 in X. laevis) against a decoy version of UniProtKB (May 2013). Carbamidomethylation of cysteines was set as a fixed modification, and $\mathrm{N}$-terminal acetylation and oxidation of methionine were set as variable modifications. Up to two missed cleavages were allowed. The initial allowed mass deviation of the precursor ion was up to $6 \mathrm{ppm}$, and for the fragment masses it was $0.5 \mathrm{Da}$. The "match between runs" option enabled transfer of identifications across samples within a time window of $2 \mathrm{~min}$ of the aligned retention times. The maximum false peptide discovery rate was specified as 0.01 . Protein titers were calculated on the basis of the raw spectral protein intensity (without normalization) of the MaxQuant software output using the total protein approach (TPA) ${ }^{8}$ according to the following relationships:

$$
\mathrm{PA}(i)=\frac{\mathrm{MS} \text { signal }(i)}{\text { total MS signal }} \times 100 \%
$$

where $\operatorname{PA}(i)$ is the abundance of protein $i$ (in \%), and

$$
c(i)=\frac{\mathrm{MS} \text { signal }(i)}{\text { total } \mathrm{MS} \text { signal } \times \mathrm{MW}(i)}
$$

where $c(i)$ is the specific concentration of protein $i$ (in $\mathrm{mol} / \mathrm{g}$ of total protein) and $\mathrm{MW}(i)$ is its molar mass (in $\mathrm{g} / \mathrm{mol}$ ).

\section{Western Blot Analysis}

Mouse organ and cell lysates were electrophoresed, transferred to nitrocellulose, and probed as described previously. ${ }^{15}$ Briefly, aliquots of whole-tissue lysates containing $10 \mu \mathrm{g}$ of total protein were separated on SDS gels and blotted onto nitrocellulose. The completeness of protein transfer was checked by Coomassie staining of the gel after blotting. After protein fixation with $0.5 \%$ glutaraldehyde, the blots were stained with Poceau $S$ to test the quality of the protein transfer. ${ }^{15}$ The fixation enabled reuse of the same blot several times, thus saving labor and increasing the comparability of the blots generated with various antibodies. Antibodies against DJ-1 (PARK 7) were purchased from Pierce/Thermo-Fisher (PAS13404, Darmstadt, Germany), ABCAM (ab18257, Cambridge, U.K.), Biozol (LS-C93055, Eching, Germany), and SigmaAldrich (SAB4500249, Taufkirchen, Germany). Antibodies against $\beta$-actin, $\beta$-tubulin, and GAPDH were obtained from Cell Signaling Technology (Leiden, The Netherlands) with catalog numbers 4967L, 2125S, and 2118, respectively. The blots were stripped with a solution containing $2 \%$ SDS and 15 $\mathrm{mM} 2$-mercaptoethanol in water at $55{ }^{\circ} \mathrm{C}$ for $1 \mathrm{~h}$. Following several washes with excess water, the blots were reused. Primary antibody binding was visualized using secondary antibodies and an enhanced chemiluminescence (ECL) detection system and scanned using an ImageQuant LAS 4000 instrument (GE Healthcare).

\section{RESULTS AND DISCUSSION}

\section{Proteomic Screens To Identify Proteins with the Most Constant Expression Levels}

SDS lysates of six mouse organs and six human cell lines were analyzed by label-free proteomics and in parallel by WB (Figure

Table 1. Summary of Previously Reported Values of the Fraction of Total Protein and Concentration of the DJ-1

\begin{tabular}{|c|c|c|}
\hline tissue/cells ${ }^{\text {ref }}$ & $\begin{array}{l}\text { fraction of total } \\
\text { protein } \pm \text { SD }(\%)\end{array}$ & $\begin{array}{l}\text { concentration } \pm \\
\mathrm{SD}(\mathrm{pmol} / \mathrm{mg})\end{array}$ \\
\hline \multicolumn{3}{|c|}{ Mouse Organs } \\
\hline brain $^{24}$ & $0.050 \pm 0.002$ & $24.9 \pm 0.9$ \\
\hline eye $^{24}$ & $0.071 \pm 0.015$ & $35.5 \pm 7.7$ \\
\hline heart $^{24}$ & $0.038 \pm 0.004$ & $19.0 \pm 1.9$ \\
\hline $\operatorname{liver}^{24}$ & $0.060 \pm 0.004$ & $29.9 \pm 2.2$ \\
\hline $\operatorname{lung}^{24}$ & $0.043 \pm 0.004$ & $21.6 \pm 2.1$ \\
\hline ovary $^{24}$ & $0.073 \pm 0.015$ & $36.5 \pm 7.4$ \\
\hline pituitary $^{24}$ & $0.087 \pm 0.006$ & $43.6 \pm 3.2$ \\
\hline prostate $^{24}$ & $0.033 \pm 0.004$ & $16.5 \pm 2.0$ \\
\hline thyroid $^{24}$ & $0.053 \pm 0.010$ & $26.3 \pm 5.1$ \\
\hline muscle $^{24}$ & $0.052 \pm 0.010$ & $26.2 \pm 4.9$ \\
\hline \multicolumn{3}{|c|}{ Human Cells and Organs } \\
\hline erythrocyte (fresh) ${ }^{25}$ & $0.062 \pm 0.015$ & $29.1 \pm 10.5$ \\
\hline colonic adenoma $\left(\mathrm{FFPE}^{a}\right)^{26}$ & $0.069 \pm 0.012$ & $34.7 \pm 5.9$ \\
\hline colonic mucosa $(\mathrm{FFPE})^{26}$ & $0.076 \pm 0.027$ & $38.8 \pm 6.9$ \\
\hline colonic adenocarcinoma $(\mathrm{FFPE})^{26}$ & $0.077 \pm 0.014$ & $38.0 \pm 13.5$ \\
\hline hepatocyte (frozen) $)^{27}$ & $0.079 \pm 0.010$ & $39.5 \pm 4.8$ \\
\hline \multicolumn{3}{|c|}{ Human Cell Lines } \\
\hline HCT116 (colon cancer) $)^{25}$ & $0.071 \pm 0.020$ & $35.7 \pm 10.2$ \\
\hline K562 (leukemia) ${ }^{25}$ & $0.112 \pm 0.004$ & $56.1 \pm 2.3$ \\
\hline MCF7 (breast cancer) ${ }^{25}$ & $0.074 \pm 0.002$ & $37.4 \pm 1.0$ \\
\hline HepG2 (hepatoma) $)^{27}$ & $0.054 \pm 0.002$ & $27.0 \pm 1.1$ \\
\hline Caco2 (colon cancer) filter ${ }^{28}$ & $0.064 \pm 0.006$ & $32.5 \pm 2.9$ \\
\hline Caco 2 plastic 3 days $^{7}$ & $0.044 \pm 0.006$ & $22.4 \pm 3.2$ \\
\hline Caco2 plastic 2 weeks $^{7}$ & $0.063 \pm 0.004$ & $31.8 \pm 2.0$ \\
\hline HeLa (cervical cancer $)^{7}$ & $0.066 \pm 0.010$ & $33.6 \pm 5.3$ \\
\hline average & $0.069 \pm 0.017$ & $34.6 \pm 8.7$ \\
\hline $\mathrm{CV}$ & 0.25 & 0.25 \\
\hline
\end{tabular}
Protein

1A-E and Table S1). Proteins exhibited a wide range of variabilities in measured expression values in these diverse systems. $\beta$-Actin and $\beta$-tubulin were in the middle of this distribution (Figure 1A) and showed considerable variation as well (Figure 1B-E). This was surprising because one would have expected widely used loading controls to be among the most stably expressed under different conditions. Instead, the protein with the most constant expression levels in mouse tissue and cultured human cells was an ubiquitously expressed enzyme, the deglycase DJ-1 (Figure 1A-E). DJ-1 is encoded by the PARK7 gene, mutations in which result in autosomal recessive early-onset Parkinson disease $7 .{ }^{16}$ Remarkably, in light of the nearly constant expression levels of this enzyme documented here, this protein has been reported to be deregulated in several cancer types (albeit often with low fold changes), and as a consequence, it has frequently been proposed as a biomarker candidate. ${ }^{17}$ Those low fold changes 
A

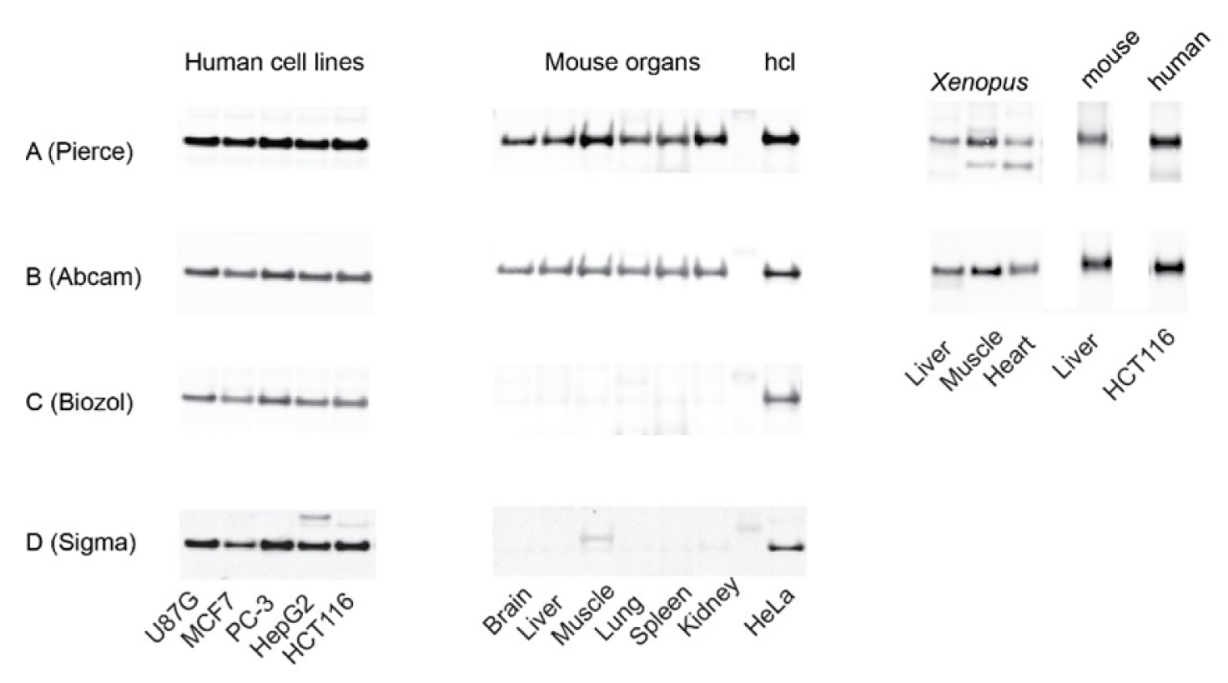

C

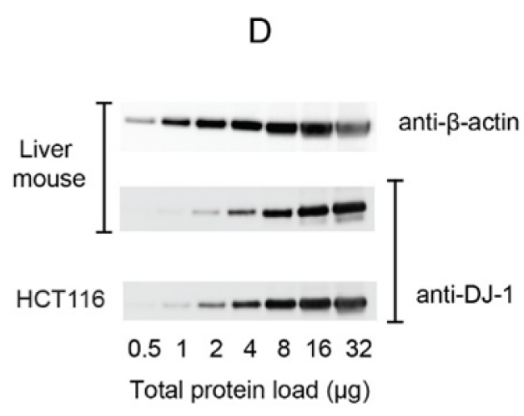

$\mathrm{E}$

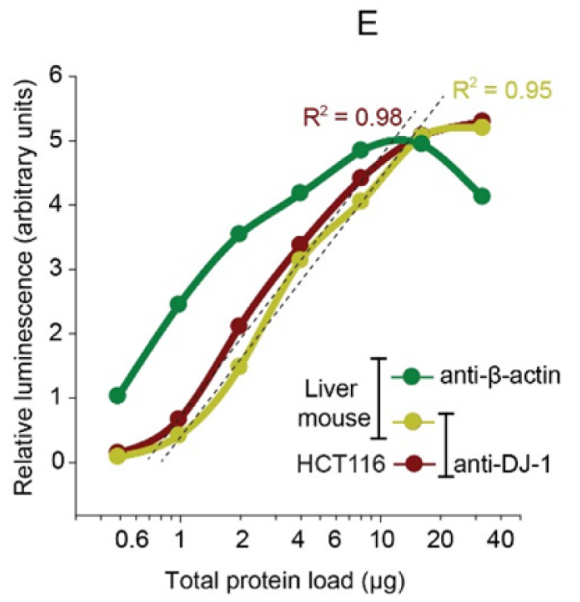

Figure 2. Performance of antibodies against DJ-1 (PARK7) protein in Western blot analysis. Antibodies from four different commercial sources (indicated in parentheses) were tested on blots with whole-cell/tissue lysates of (A) cultured human cells, (B) mouse tissues and HeLa cells, and (C) Xenopus laevis with mouse liver and human cells. Each of the antibodies used was declared by the manufacturer to stain human and mouse DJ-1, but no information on the reactivities these antibodies against DJ-1 in X. laevis was available. (D) Total protein dilution series using whole tissue and cell lysate. DJ-1 protein was visualized using antibodies B (Abcam). (E) Quantification of blots shown in (D). Each data point shows an average of two independent measurements. The dashed lines show linear regression of the data in the range of $1-10 \mu \mathrm{g}$ total protein.

were often based on loading controls, which varied much more than DJ-1 in our data sets.

In contrast to relative analyses, the total protein approach (TPA $)^{7,8}$ allows absolute quantitation based on normalized intensities, thereby enabling the comparison of protein titers among different archival data sets generated using different peptide fractionation and mass spectrometric platforms. We took advantage of this feature to compare DJ-1 concentrations that were assessed in several previously published studies from our laboratory. The levels of DJ-1 turned out to be similarly stable within these data sets and between mouse and human (Table 1 and Figure 1F). The protein constitutes $0.069 \pm$ $0.017 \%$ of total cellular protein and occurs at a specific concentration of $34.6 \pm 8.7 \mathrm{pmol} / \mathrm{mg}$ of total protein. The assessed DJ-1 titer values vary up to 2 -fold among different tissues and cell lines. Since DJ-1 is structurally conserved down to prokaryotes, ${ }^{18}$ we asked whether its abundance is also evolutionarily conserved. We prepared and analyzed wholetissue lysates of liver, heart, skeletal muscle, and oocytes from the African frog Xenopus. TPA analysis revealed that the concentrations of DJ-1 in the amphibian tissues and cells are similar to those in mammals (Figure $1 \mathrm{G}$ and Figure 2C). This finding suggests that the cellular concentration of DJ-1 is wellmaintained in diverse vertebrate species.

\section{DJ-1 as a Loading Control in Western Blot Analysis}

$\mathrm{DJ}-1$ is a $20 \mathrm{kDa}$ cytoplasmic protein, and therefore, it is easily extractable as well as quantitatively transferable from polyacrylamide gels to blotting membranes. Since small proteins often dissociate from the blotting membrane, ${ }^{19}$ we routinely fix proteins after the blotting procedure using diluted glutaraldehyde over a short time. ${ }^{15,20,21}$ Blots with fixed proteins can be stripped and reused for probing with different antibodies. This procedure allows more accurate comparison of different antigens on a single blot compared with several blots. Care should be taken to avoid "overfixation", which can affect the antibody-antigen interaction. The expression levels of DJ-1 are $10-100$-fold lower than those of $\beta$-actin, $\beta$-tubulin, and GAPDH, and thus, problems with band saturation ${ }^{2}$ can be avoided. Currently there are several different antibodies against 
DJ-1 on the market. We tested the performance of four different products that have been declared as reactive against human and mouse DJ-1 on WB (Figure 2). All four antibodies detected the antigen in human cell line samples in a uniform way (Figure 2A). Two antibodies stained with a small variation observed in the proteomics analyses of human and mouse proteins (Figure 2B). These two antibodies were also useful for detection of Xenopus DJ1 protein, but the intensity of staining was weaker than for mouse and human controls (Figure 2C). These results also highlight one key limitation of the WB technique, namely, the properties of antibodies that often lack desired specificity and affinity to the intended antigen.

Next we analyzed the intensity of antibody staining across a series of sample dilutions (Figure 2D,E). This demonstrated the utility of the anti-DJ1 antibodies (antibodies B) as a quantification reference for sample loads from about 1 to about $20 \mu \mathrm{g}$ of total protein. In this range, staining with $\beta$-actin showed saturation, which disqualifies this protein from use as a loading control. Western blotting is ubiquitously used and also frequently demanded by reviewers for validation of proteomic results. In view of the work presented here, it is our opinion that $\mathrm{WB}$ can at best play only only a supportive role in the evaluation of proteomic results. WB can provide unambiguous results only when thoroughly tested antibodies are used, which is rarely the case, as has been pointed out recently. ${ }^{6,22}$ In this context, it should be considered whether another proteomic analysis using a different proteomic platform would be a better validation of proteomic data. For instance, this is readily achieved by varying the sample preparation method, digestion strategy, or peptide prefractionation or alternatively by employing different mass spectrometers. It is worth emphasizing that the DJ-1 concentrations presented in this work were calculated from several unrelated data sets that were generated using various peptide fractionation schemes and different mass spectrometers operating in distinct fragmentation modes (CID or HCD). This stresses the advantages of robust comparison of proteomics data, as is for instance possible with the TPA approach.

\section{CONCLUSIONS}

Here we have established that the quantitative and unbiased nature of MS-based proteomics can be used to advantage when selecting proteins with stable expression patterns across diverse biological systems. Specifically, we have identified a protein marker for proteomic normalization in MS-based experiments as well as in Western blot analyses in human, mouse, and amphibian tissues and cells. The approach suggested here can be used more widely to determine the suitability of proteins or sets of proteins as loading and normalization controls for any biological system. As we have shown here, historically selected "household proteins" may not be the most suitable for this task for technical and biological reasons. Conversely, expression data across diverse systems can inform the selection of proteins to serve as biomarkers.

\section{ASSOCIATED CONTENT}

\section{S Supporting Information}

The Supporting Information is available free of charge on the ACS Publications website at DOI: 10.1021/acs.jproteome.6b00403.

Protein content and concentration of identified proteins, including the DJ-1 protein (Table S1) (XLSX)

\section{AUTHOR INFORMATION}

\section{Corresponding Author}

*Address: Biochemical Proteomics Group, Department of Proteomics and Signal Transduction, Max Planck Institute of Biochemistry, 82152 Martinsried, Germany. E-mail: jwisniew@ biochem.mpg.de. Tel.: +498985782205.

Notes

The authors declare no competing financial interest.

RAW files and the MaxQuant search results have been deposited in the PRIDE repository database ${ }^{23}$ with the data set identifier PXD003422.

\section{ACKNOWLEDGMENTS}

We thank Mrs. Katharina Zettl for brilliant technical assistance, Prof. Hermann Koepsell and Dr. Thorsten Keller (University of Würzburg) for kindly providing the oocyte lysate, and Dr. Marcus Röschle (Max Planck Institute of Biochemistry, Martinsried) for providing tissues from Xenopus laevis. This work was supported by the German Research Foundation (DFG/Gottfried Wilhelm Leibniz Prize).

\section{REFERENCES}

(1) Towbin, H.; Staehelin, T.; Gordon, J. Electrophoretic transfer of proteins from polyacrylamide gels to nitrocellulose sheets: procedure and some applications. Proc. Natl. Acad. Sci. U. S. A. 1979, 76 (9), 4350-4.

(2) Gorr, T. A.; Vogel, J. Western blotting revisited: critical perusal of underappreciated technical issues. Proteomics: Clin. Appl. 2015, 9 (34), 396-405.

(3) Welinder, C.; Ekblad, L. Coomassie staining as loading control in Western blot analysis. J. Proteome Res. 2011, 10 (3), 1416-9.

(4) Aldridge, G. M.; Podrebarac, D. M.; Greenough, W. T.; Weiler, I. $\mathrm{J}$. The use of total protein stains as loading controls: an alternative to high-abundance single-protein controls in semi-quantitative immunoblotting. J. Neurosci. Methods 2008, 172 (2), 250-4.

(5) Eaton, S. L.; Roche, S. L.; Llavero Hurtado, M.; Oldknow, K. J.; Farquharson, C.; Gillingwater, T. H.; Wishart, T. M. Total protein analysis as a reliable loading control for quantitative fluorescent Western blotting. PLoS One 2013, 8 (8), e72457.

(6) Baker, M. Reproducibility crisis: Blame it on the antibodies. Nature 2015, 521 (7552), 274-6.

(7) Wisniewski, J. R.; Ostasiewicz, P.; Dus, K.; Zielinska, D. F.; Gnad, F.; Mann, M. Extensive quantitative remodeling of the proteome between normal colon tissue and adenocarcinoma. Mol. Syst. Biol. 2012, 8, 611 .

(8) Wisniewski, J. R.; Rakus, D. Multi-enzyme digestion FASP and the 'Total Protein Approach'-based absolute quantification of the Escherichia coli proteome. J. Proteomics 2014, 109, 322-331.

(9) Wisniewski, J. R.; Koepsell, H.; Gizak, A.; Rakus, D. Absolute protein quantification allows differentiation of cell-specific metabolic routes and functions. Proteomics 2015, 15 (7), 1316-25.

(10) Wisniewski, J. R; Gaugaz, F. Z. Fast and sensitive total protein and Peptide assays for proteomic analysis. Anal. Chem. 2015, 87 (8), 4110-6.

(11) Wisniewski, J. R.; Mann, M. Consecutive proteolytic digestion in an enzyme reactor increases depth of proteomic and phosphoproteomic analysis. Anal. Chem. 2012, 84 (6), 2631-7.

(12) Wisniewski, J. R. Quantitative evaluation of FASP and MED FASP protocols. Anal. Chem. 2016, 88 (10), 5438-43.

(13) Wisniewski, J. R.; Mann, M. Consecutive proteolytic digestion in an enzyme reactor increases depth of proteomic and phosphoproteomic analysis. Anal. Chem. 2012, 84 (6), 2631-7.

(14) Cox, J.; Mann, M. MaxQuant enables high peptide identification rates, individualized p.p.b.-range mass accuracies and proteome-wide protein quantification. Nat. Biotechnol. 2008, 26 (12), 1367-72. 
(15) Ziolkowski, P.; Gamian, E.; Osiecka, B.; Zougman, A.; Wisniewski, J. R. Immunohistochemical and proteomic evaluation of nuclear ubiquitous casein and cyclin-dependent kinases substrate in invasive ductal carcinoma of the breast. J. Biomed. Biotechnol. 2009, 2009, 919645.

(16) Bonifati, V.; Rizzu, P.; van Baren, M. J.; Schaap, O.; Breedveld, G. J.; Krieger, E.; Dekker, M. C.; Squitieri, F.; Ibanez, P.; Joosse, M.; van Dongen, J. W.; Vanacore, N.; van Swieten, J. C.; Brice, A.; Meco, G.; van Duijn, C. M.; Oostra, B. A.; Heutink, P. Mutations in the DJ-1 gene associated with autosomal recessive early-onset parkinsonism. Science 2003, 299 (5604), 256-9.

(17) Cao, J.; Lou, S.; Ying, M.; Yang, B. DJ-1 as a human oncogene and potential therapeutic target. Biochem. Pharmacol. 2015, 93 (3), 241-50.

(18) Lee, S. J.; Kim, S. J.; Kim, I. K.; Ko, J.; Jeong, C. S.; Kim, G. H.; Park, C.; Kang, S. O.; Suh, P. G.; Lee, H. S.; Cha, S. S. Crystal structures of human DJ-1 and Escherichia coli Hsp31, which share an evolutionarily conserved domain. J. Biol. Chem. 2003, 278 (45), 44552-9.

(19) Karey, K. P.; Sirbasku, D. A. Glutaraldehyde fixation increases retention of low molecular weight proteins (growth factors) transferred to nylon membranes for western blot analysis. Anal. Biochem. 1989, 178 (2), 255-9.

(20) Zougman, A.; Mann, M.; Wisniewski, J. R. Identification and characterization of a novel ubiquitous nucleolar protein 'NARR' encoded by a gene overlapping the rab34 oncogene. Nucleic Acids Res. 2011, 39 (16), 7103-13.

(21) Zougman, A.; Ziolkowski, P.; Mann, M.; Wisniewski, J. R. Evidence for insertional RNA editing in humans. Curr. Biol. 2008, 18 (22), 1760-5.

(22) Bradbury, A.; Pluckthun, A. Reproducibility: Standardize antibodies used in research. Nature 2015, 518 (7537), 27-9.

(23) Vizcaino, J. A.; Deutsch, E. W.; Wang, R.; Csordas, A.; Reisinger, F.; Rios, D.; Dianes, J. A.; Sun, Z.; Farrah, T.; Bandeira, N.; Binz, P. A.; Xenarios, I.; Eisenacher, M.; Mayer, G.; Gatto, L.; Campos, A.; Chalkley, R. J.; Kraus, H. J.; Albar, J. P.; Martinez-Bartolome, S.; Apweiler, R.; Omenn, G. S.; Martens, L.; Jones, A. R.; Hermjakob, H. ProteomeXchange provides globally coordinated proteomics data submission and dissemination. Nat. Biotechnol. 2014, 32 (3), 223-6.

(24) Wisniewski, J. R.; Gizak, A.; Rakus, D. Integrating Proteomics and Enzyme Kinetics Reveals Tissue-Specific Types of the Glycolytic and Gluconeogenic Pathways. J. Proteome Res. 2015, 14 (8), 3263-73.

(25) Wisniewski, J. R.; Koepsell, H.; Gizak, A.; Rakus, D. Absolute protein quantification allows differentiation of cell-specific metabolic routes and functions. Proteomics 2015, 15 (7), 1316-25.

(26) Wisniewski, J. R.; Dus-Szachniewicz, K.; Ostasiewicz, P.; Ziolkowski, P.; Rakus, D.; Mann, M. Absolute Proteome Analysis of Colorectal Mucosa, Adenoma, and Cancer Reveals Drastic Changes in Fatty Acid Metabolism and Plasma Membrane Transporters. J. Proteome Res. 2015, 14 (9), 4005-18.

(27) Wisniewski, J. R.; Vildhede, A.; Noren, A.; Artursson, P. Indepth quantitative analysis and comparison of the human hepatocyte and hepatoma cell line HepG2 proteomes. J. Proteomics 2016, 136, 234-47.

(28) Ölander, M.; Wisniewski, J. R.; Matsson, P.; Lundquist, P.; Artursson, P. The proteome of filter-grown Caco-2 cells with a focus on proteins involved in drug disposition. J. Pharm. Sci. 2016, 105, $817-827$. 